\title{
Increased motor unit fibre density in the external anal sphincter muscle in ano-rectal incontinence: a single fibre EMG study
}

\author{
M E NEILL A ND M S W A S H \\ From St Mark's Hospital and The London Hospital, London
}

SUMMARY The motor unit fibre density in the external anal sphincter muscle has been measured in 13 normal subjects aged 18 to 78 years, and in 14 patients with ano-rectal incontinence, aged 17 to 72 years. The mean fibre density in the normal subjects was $1 \cdot 5 \pm 0 \cdot 16$, and in the incontinent subjects it was $2 \cdot 17 \pm 0.28(\mathrm{p}<0.001)$. These findings provide support for the suggestion that ano-rectal incontinence commonly has a neurogenic basis.

Investigation of patients with ano-rectal incontinence has relied hitherto on anal pressure studies supported by EMG and more recently, by study of the anal reflex. ${ }^{1}$ Parks, Swash and Urich ${ }^{2}$ reported histological abnormalities in the voluntary anal sphincter musculature in patients with anorectal incontinence and suggested that the innervation of the external anal sphincter and puborectalis muscles was damaged in these patients. This suggestion has been supported by the observation of abnormalities in small nerves supplying the external anal sphincter muscle itself ${ }^{2}$ and by quantitative histometric studies of the external anal sphincter, puborectalis and levator ani muscles in a group of patients with anorectal incontinence matched for age with a group of normal subjects. ${ }^{34}$

Conventional EMG studies of the external anal sphincter have not proved useful in clinical practice although they can provide information about the pattern of voluntary control of the external anal sphincter muscle, especially in patients with cauda equina lesions. ${ }^{5}$ In order to study the functional disorder in the external anal sphincter in patients with ano-rectal incontinence we have used single fibre EMG. By this technique a quantitative estimate of the mean number of muscle fibres (from 20 different recordings) belonging to a motor unit within the uptake area of the recording electrode, the motor unit fibre density, may be

Address for reprint requests: Dr M Swash, Department of Neurology, The London Hospital, London E1 1 BB.

Accepted 13 December 1979 obtained. ${ }^{\tau}$ The fibre density may be increased in both neurogenic and myopathic disorders, but in a muscle known not to be affected by a myopathic process an increased fibre density is an index of reinnervation. Other parameters, such as measurement of the neuromuscular jitter and impulse blocking ${ }^{8} 9$ may also be studied.

In this report we describe a method for obtaining single fibre EMG recordings in the external anal sphincter muscle in human subjects. We have used this method to measure the fibre density in this muscle in a group of normal subjects, and in a group of patients with ano-rectal incontinence. The results are consistent with our suggestion ${ }^{2-4}$ that ano-rectal incontinence can occur from damage to the innervation of the sphincter musculature.

\section{Methods}

Single fibre EMG recordings were made with a Medelec MS6 EMG apparatus, Medelec SF25 single fibre EMG electrodes and low and high frequency filter settings of $500 \mathrm{~Hz}$ and $16 \mathrm{~K} \mathrm{~Hz}$. In single fibre EMG recordings in limb muscles a triggering potential is accepted only if its amplitude is greater than $200 \mu \mathrm{V}$, and its rise time is less than 300 ms. $^{8}{ }^{9}$ However motor unit action potentials recorded in the external anal sphincter muscle with conventional EMG are smaller than those recorded in other striated muscles; Jesel, Isch-Treussard and Isch $^{6}$ found a mean amplitude of $200-600 \mu \mathrm{V}$, and a maximal amplitude of 
$3 \mathrm{mV}$. The low amplitude of motor unit action potentials in the external anal sphincter is due to the small size of the muscle fibres in this muscle. In a histometric study we found that the mean diameter of muscle fibres in the external anal sphincter in normal subjects was less than $30 \mu \mathrm{m} .{ }^{4}$ We decided, therefore, to accept triggering potentials greater than $150 \mu \mathrm{V}$ in our single fibre EMG studies of this muscle.

Technique: In normal subjects the external sphincter muscle shows tonic resting activity, but these potentials are small and show an infrequent and irregular firing pattern. It is difficult to voluntarily activate motor units in the external anal sphincter to a consistency adequate for single fibre EMG recordings to be made. In order to obtain a slight degree of continuous activity in the muscle we have utilised the activating effect of slight traction on the sphincter ring.

Each patient was placed in the left lateral position. A Miller-Abbott balloon was inserted into the lower rectum and distended with $30 \mathrm{ml}$ of air and $150 \mathrm{~g}$ traction was applied by means of a weighted cord. This proved sufficient to induce a constant, slight amount of activity in the external sphincter muscle. A suitable ground lead was attached to the left thigh. The single fibre EMG electrode was inserted, without anaesthetic, into the external anal sphincter muscle lateral to the anal margin on either side, and recordings made with the electrode directed both anteriorly and posteriorly in the muscle. Most of the recordings were made in the superficial part of the muscle. As in fibre density measurements in other muscles ${ }^{9}$ the mean number of single muscle fibre action potentials recorded in 20 different electrode positions was taken as the fibre density. Usually only two skin penetrations were required. The fibre density was measured on both sides of the circular external anal sphincter muscle, but most of the recordings were made on the dependent left side. All the potentials were recorded for subsequent analysis.

Patients: Thirteen subjects, eight of whom were women, served as controls. These volunteer patients were attending St Mark's Hospital for treatment of disorders not affecting the perineum, anus or rectum, such as inguinal hernia, carcinoma of the colon and cholecystitis. Their ages ranged from 18 to 78 years (mean $51 \mathrm{yr}$ ). Examination of the perineum, anus and rectum before single fibre EMG revealed no abnormality, and there was no clinical evidence of disease of the lumbosacral spine or nerve roots.

Fourteen patients with ano-rectal incontinence were studied. All these patients were women. Their ages ranged from 17 to 72 years (mean $42 \mathrm{yr}$ ). Clinical details are given in the table.

Table Summary of clinical and EMG data.

\begin{tabular}{|c|c|c|c|c|c|c|c|c|c|c|}
\hline \multirow{2}{*}{$\begin{array}{l}\text { Case } \\
\text { no }\end{array}$} & \multirow{2}{*}{$\begin{array}{l}\text { Sex/ } \\
\text { age } \\
(y r)\end{array}$} & \multirow{2}{*}{$\begin{array}{l}\text { Type } \\
\text { of } F I\end{array}$} & \multirow{2}{*}{$\begin{array}{l}\text { Duration } \\
\text { of } F I \\
(y r)\end{array}$} & \multirow{2}{*}{$\begin{array}{l}\text { Defecation } \\
\text { straining }\end{array}$} & \multirow{2}{*}{$\begin{array}{l}\text { Rectal } \\
\text { prolapse }\end{array}$} & \multirow{2}{*}{$\begin{array}{l}\text { Perineal } \\
\text { descent }\end{array}$} & \multirow{2}{*}{ Obstetric history para. } & \multirow[t]{2}{*}{ Other clinical features } & \multicolumn{2}{|c|}{ Single fibre EMG } \\
\hline & & & & & & & & & $\begin{array}{l}\text { Fibre } \\
\text { density }\end{array}$ & $\begin{array}{l}\text { Mean MUAP } \\
\text { duration } \\
(\mathrm{ms})\end{array}$ \\
\hline 1 & $\mathbf{F} / 17$ & Loose & 8 & +++ & 0 & + & 0 & $\begin{array}{l}\text { Father has myotonic } \\
\text { dystrophy }\end{array}$ & $1 \cdot 8$ & 0.45 \\
\hline 2 & $\mathbf{F} / 21$ & Solid & 4 & +++ & +++ & $++t$ & $0 \quad 0$ & Rectopexy & $2 \cdot 0$ & 0.76 \\
\hline 3 & $\mathbf{F} / 36$ & Solid & 11 & $+t+$ & $++t$ & $+t+$ & $\begin{array}{l}\text { Precipitate delivery } \\
2 \text { incontinence began } \\
\text { after childbirth ( } 2 \text { nd) }\end{array}$ & $\begin{array}{l}\text { Long history } \\
\text { constipation }\end{array}$ & $2 \cdot 5$ & $2 \cdot 4$ \\
\hline 4 & $F / 38$ & Solid & 1 & 0 & +++ & +++ & 1 precipitate delivery & $\begin{array}{l}\text { Rectopexy post anal } \\
\text { repair previously }\end{array}$ & $2 \cdot 3$ & $2 \cdot 3$ \\
\hline 5 & $F / 40$ & Solid & 10 & 0 & 0 & ++ & 3 perineal tear & $\begin{array}{l}\text { Incontinence worse } \\
\text { after each delivery }\end{array}$ & $2 \cdot 0$ & $1 \cdot 0$ \\
\hline 6 & $F / 41$ & Loose & 7 & 0 & 0 & + & 3 difficult deliveries & & $1 \cdot 9$ & $1 \cdot 0$ \\
\hline 7 & $F / 43$ & Solid & 9 & 0 & 0 & + & 3 difficult deliveries & Crohn's disease & $2 \cdot 35$ & $1 \cdot 5$ \\
\hline 8 & F/49 & Solid & 10 & $+t+$ & $+t+$ & $+t$ & 3 precipitate deliveries & & $2 \cdot 4$ & $1 \cdot 0$ \\
\hline 9 & $\mathbf{F} / 50$ & Solid & $2 / 3$ & + & 0 & + & 4 severe perineal tears & $\begin{array}{l}\text { Vaginal repair } \\
3 \text { lumbar laminectomies }\end{array}$ & $2 \cdot 7$ & $2 \cdot 0$ \\
\hline 10 & $\mathbf{F} / 60$ & Loose & 10 & +++ & $\mathbf{0}$ & + & $\mathbf{0}$ & $\begin{array}{l}\text { Vaginal repair } \\
\text { hysterectomy }\end{array}$ & $1 \cdot 85$ & $1 \cdot 1$ \\
\hline 11 & $\mathbf{F} / 61$ & Solid & 3 & +++ & $+t+$ & $++t$ & 3 normal deliveries & $\begin{array}{l}\text { Rectopexy history of } \\
\text { constipation }\end{array}$ & $2 \cdot 0$ & $1 \cdot 1$ \\
\hline 12 & $\mathbf{F} / 62$ & Loose & 5 & +++ & 0 & ++ & 2 caesarian sections & $\begin{array}{l}\text { Vaginal repair } \\
\text { hysterectomy }\end{array}$ & $2 \cdot 0$ & 0.45 \\
\hline $\begin{array}{l}13 \\
14\end{array}$ & $\begin{array}{l}\text { F/65 } \\
\text { F/72 }\end{array}$ & $\begin{array}{l}\text { Solid } \\
\text { Solid }\end{array}$ & $\begin{array}{l}5 \\
2\end{array}$ & $\begin{array}{l}+++ \\
+++\end{array}$ & $0_{0}^{++t}$ & $\begin{array}{l}++ \\
++\end{array}$ & $\begin{array}{l}1 \text { normal delivery } \\
1 \text { prolonged labour }\end{array}$ & $\begin{array}{l}\text { Rectopexy anal pain } \\
\text { Vaginal repair } \\
\text { maximal anal dilation }\end{array}$ & $\begin{array}{l}2 \cdot 2 \\
2 \cdot 4\end{array}$ & $\begin{array}{l}1 \cdot 6 \\
1 \cdot 2\end{array}$ \\
\hline
\end{tabular}

$\mathrm{FI}=$ faecal incontinence $;++=$ severe $;+=$ moderate $;+=$ mild $;$ MUAP=motor unit action potential. 


\section{Results}

In the 13 normal subjects the fibre density ranged from 1.3 to 1.8 (mean 1.5 , SD $0 \cdot 16$ ). The relation between fibre density and age in these subjects is shown in fig 1. There was an increase in fibre density with age, which was most evident after the age of 60 years. In the youngest subject studied, a woman aged 18 years, the fibre density was slightly higher than in two subjects aged 20 to 30 years. A typical pair of potentials recorded from one of these normal subjects is shown in fig 2 . The neuromuscular jitter was not measured, but no potential pair showed a jitter greater than $50 \mathrm{~ms}$. All the triggering potentials were greater than $200 \mu \mathrm{V}$ in amplitude.

In the 14 patients with ano-rectal incontinence the fibre density ranged from 1.8 to 2.7 (mean $2 \cdot 17$, SD $0 \cdot 28$ ). The range of fibre densities in the normal subjects and incontinent patients did not overlap and the mean values in the two groups

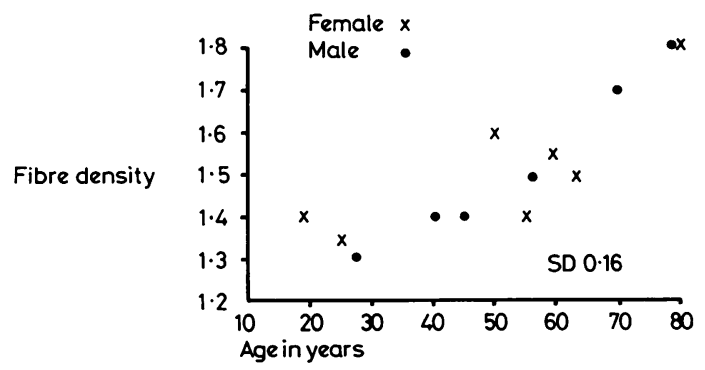

Fig 1 The relation between fibre density in the external anal sphincter muscle and age, in 13 normal subjects.

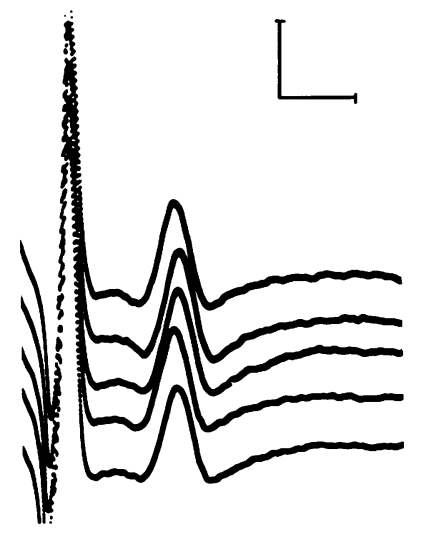

Fig 2 A double potential, showing a normal jitter. Scale: $1 \mathrm{mV}, 1 \mathrm{~ms}$. were significantly different. (Student's two tailed $t$ test; $\mathrm{p}<0.001)$. The fibre densities in the incontinent subjects are shown, compared to the normal values in relation to age, in fig 3 . A stable motor unit action potential showing an increased number of single muscle fibre action potentials, without increased jitter or impulse blocking, is shown in fig 4. In some potentials individual spike components showed an increased jitter and impulse blockings were seen in some of these. Rarely, blocking of two components was seen (fig 5), an indication of failure of transmission at an axonal branch in the terminal innervation.

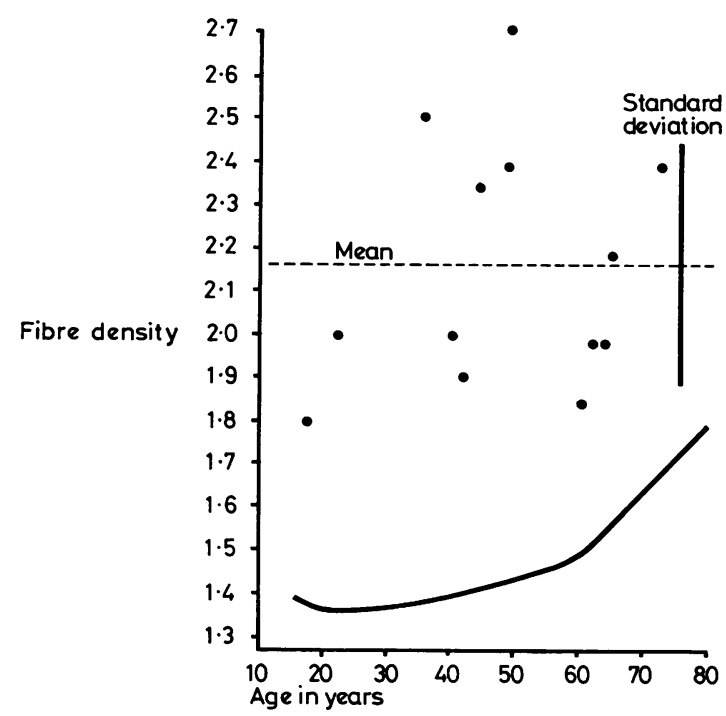

Fig 3 Fibre density in the external anal sphincter muscle, plotted against age, in 14 patients with ano-rectal incontinence. The data from the normal subjects are shown by the thicker line.

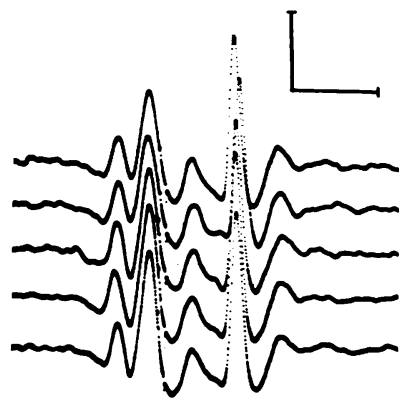

Fig 4 A stable motor unit action potential consisting of five separate components recorded in the external anal sphincter muscle of a patient with incontinence (case 3). Scale: $1 \mathrm{mV}, 1 \mathrm{~ms}$. 


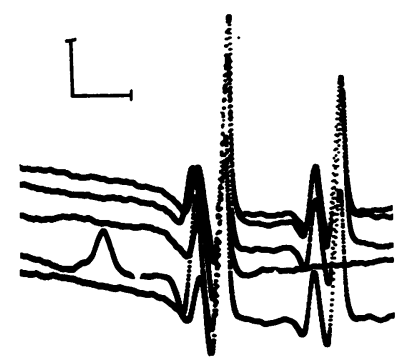

Fig 5 A potential with four components. Since the configuration of the second pair of components differs slightly from that of the first pair, this recording is interpreted as representing 'neural blocking' of the second pair of components rather than intermittent double discharges. Scale: $1 \mathrm{mV}, 1 \mathrm{~ms}$.

\section{Discussion}

In most subjects single fibre EMG assessment of the external anal sphincter is neither difficult nor painful. Some subjects were distressed by their inability to observe the procedure of electrode placement, as in ordinary EMG examinations, but the use of a weighted intra-rectal balloon to induce slight activity in the external anal sphincter made it relatively easy to record enough potentials for fibre density measurements in about 20 minutes. In patients with incontinence it was more difficult to obtain recordings of 20 different motor unit action potentials.

We have used a slightly lower amplitude criterion for the triggering potential in our work than was used by Stålberg and Thiele ${ }^{7}$ in their study of the fibre density in the extensor digitorum communis muscle,$^{79}$ because the mean diameter of muscle fibres in the external anal sphincter muscle is less than half that found in limb muscles of normal subjects. ${ }^{4}$ Most of the triggering potentials, however, recorded in the external anal sphincter in our subjects were greater than $300 \mu \mathrm{V}$, and all were greater than $200 \mu \mathrm{V}$. The neuromuscular jitter was not measured systematically, but was always less than $50 \mu \mathrm{s}$.

In the normal subjects the mean fibre density in the external anal sphincter muscle was $1 \cdot 5$, a value similar to that found in other striated muscles. ${ }^{79}$ No difference was found between men and women of similar age. The fibre density was slightly increased in subjects older than 60 years, as in other muscles. ${ }^{79}$ Further, the slightly higher fibre density found in the youngest subject studied (fig 1) is consistent with the higher fibre density found in the extensor digitorum communis in normal subjects less than 10 years of age. ${ }^{9}$
The fibre density was increased in the external anal sphincter muscle in all the patients with incontinence. In one patient, aged 17 years (case 1) the fibre density was $1 \cdot 8$, a value the same as that found in an 80 year old normal subject. This patient (case 1) was chronically constipated and was incontinent only for liquid stool. Three other patients (cases 6, 10 and 12) whose fibre densities were $1.9,1.85$ and 2.0 respectively, were also incontinent only for liquid stool. The other patients, whose fibre densities ranged from 2.0 to 2.7 were incontinent for both liquid and solid faeces. There was thus a relationship between the severity of incontinence and the fibre density in the external anal sphincter muscle. No relationship between duration of incontinence and fibre density was observed; this probably reflects the various factors leading to incontinence in these patients.

All the patients with incontinence in the present series were women. Nine had a history of abnormal or difficult deliveries with trauma to the pelvic floor musculature, but three had never been pregnant and in two childbirth had been normal. Prolonged and repeated defaecation straining was admitted by nine patients (table), including all those who had not experienced a difficult delivery, or who had not been pregnant. One patient, case 14 , became incontinent of faeces after a maximal anal dilatation; this procedure probably damaged the internal anal sphincter, the external sphincter having been injured previously. These patients are thus similar to those studied previously. ${ }^{2-4}$

The pathogenesis of idiopathic ano-rectal incontinence is not well understood. Parks and Swash have reported histological evidence of denervation in the external anal sphincter and puborectalis muscles of patients with ano-rectal incontinence ${ }^{24}$ and have suggested that this might result from damage to the pudendal nerves by entrapment beneath the sacrospinous ligaments and perhaps, by stretch injury to the terminal segments of the nerves caused by descent of the perineal floor during defaecation straining. ${ }^{2} 3$ The finding of an increased motor unit fibre density in the external anal sphincter muscle in patients with ano-rectal incontinence is consistent with this hypothesis; an increased fibre density can be correlated with reinnervation, and fibre type grouping is a feature of the histological abnormality in the sphincter musculature in patients with ano-rectal incontinence. ${ }^{2-4}$ Myopathic disorders, which may also be associated with an increased fibre density in single fibre EMG recordings ${ }^{9}$ can be excluded as a cause of ano-rectal incontinence by the clinical ${ }^{2}$ and histological features. ${ }^{2-4}$ Further, we have ex- 
amined the external anal sphincter muscle by single fibre EMG in two patients with incomplete cauda equina lesions and have found the fibre density to be increased in both patients.

Single fibre EMG seems to be a useful technique for study of the functional disorder in the external anal sphincter muscle in patients with incontinence. Since it is a quantitative method it may prove particularly useful for assessing changes in the external anal sphincter muscle occurring during the natural history of perineal disorders or of their treatment. However, comparison of fibre density studies with other techniques such as pressure measurements within the anal canal, both in incontinence and in other ano-rectal disorders will be important before the role of single fibre EMG in the clinical investigation of these disorders can be established.

\section{References}

1 Henry MM, Swash M. Assessment of pelvic floor disorders and incontinence by electrophysiological recording of the anal reflex. Lancet 1978; 1: $1290-1$.
2 Parks AG, Swash M, Urich H. Sphincter denervation in ano-rectal incontinence and rectal prolapse. Gut 1977; 18:656-65.

3 Parks AG, Swash M. Denervation of the anal sphincter causing idiopathic ano-rectal incontinence. J $R$ Coll Surg Edinb 1979; 24:94-6.

4 Beersiek F, Parks AG, Swash M. Pathogenesis of ano-rectal incontinence, a histometric study of the anal sphincter musculature. $J$ Neurol Sci 1979; 42:111-27.

5 Chantrain A, Lloyd K, Swinyard CA. The sphincter ani externus in spina bifida and myelomeningocoele. J Urol 1966; 95:250-6.

6 Jesel M, Isch-Treussard C, Isch F. Electrography of striated muscle of anal urethral sphincters. In: Desmedt JE, ed. New Developments in Electromyography and Clinical Neurophysiology. Basel: Karger, 1973:406-20.

7 Stålberg E, Thiele B. Motor unit fibre density in the extensor digitorum communis muscle. $J$ Neurol, Neurosurg Psychiatry 1975; 38:874-80.

8 Ekstedt J. Human single muscle fibre action potentials. Acta Physiol Scand (Suppl 226) 1964; 61:1-96.

9 Stålberg E. Trontelj JV. Single fibre electromyography. London: Mirvalle Press, 1979. 